\title{
REPENSANDO A LITERATURA COMPARADA: EDWARD SAID E FREDRIC JAMESON
}

Sérgio Luiz Prado Bellei

UFSC

\section{RESUMO:}

As obras de Edward Said e Fredric Jameson representam, no contexto da crítica literária e cultural da atualidade, projetos alternativos para restaurar a validade do estudo histórico na leitura de textos, e isto na dimensão de poder globalizante que compreende as culturas metropolitanas e periféricas. Enquanto Jameson tenta situar tais textos em suas desigualdades e no contexto de uma história única e última e do sistema ideológico que os explica de forma mais completa (o Marxismo), Said percebe tais textos a partir da prática relativamente livre do crítico que, em precário equilíbrio entre cultura e sistema de pensamento $e$ munido de uma ética humanitária de valor universal, tenta produzir uma leitura em contraponto dirigida para a percepção das histórias do outro cultural reprimidas pelas estratégias discursivas imperiais. PALAVRAS-CHAVE:

Literatura Comparada, Edward Said, Fredric Jameson, Teoria Literária

O que torna as obras de Said e a de Jameson um tanto anômalas no contexto acadêmico metropolitano e interessantes fora dele é a decisão crítica de pensar a teoria literária como inseparável de uma história de opressão e violência, ou seja, como inseparável da dimensão do "Terceiro Mundo" (quer esteja ela localizada no centro, quer na periferia) e como caracterizada pelo esforço para ler também e contrastivamente a produção textual desse outro 
mundo, agora visto lado a lado com a tradição clássica ocidental. Vale dizer, tanto Jameson quanto Said insistem na necessidade de uma perspectiva globalizante na leitura de textos, ou seja, na necessidade de uma perspectiva comparatista a ser posta em prática por uma Literatura Comparada inseparável de uma dimensão política. A prática de leitura de texto entendida como ligada ao político e ao social, embora significativamente diversa nos dois teóricos, deixa entretanto entrever certas afinidades, particularmente visíveis no que concerne à definição do texto literário ou cultural e nas formas pelas quais tal texto pode e deve ser lido em um contexto político de opressão e resistência. Tanto para Said como para Jameson, o tex to literário ou cultural deve ser pensado como uma prática discursiva em íntimo relacionamento com outras práticas discursivas existentes na estrutura social e histórica. Não se trata mais de olhar o texto como um objeto estético em esplendoroso isolamento, como era o caso em práticas do estruturalismo ou da nova crítica. Mas, uma vez colocado o texto como discurso entre outros discursos, resta perguntar sobre as formas de relacionamento de textos nesse campo intertextual. De que forma, em outras palavras, um objeto cultural qualquer (um romance ou uma forma arquitetônica) se relaciona com um discurso racial, político, ou econômico? A resposta a essa pergunta, tanto em Said como em Jameson, nunca estará muito distante do conceito, proposto por Walter Benjamin, de que "não há documento de civilização que não seja, ao mesmo tempo, um documento de barbárie".' Jameson, por exemplo, em "Marxism and Teaching", repete Benjamin ao dizer que "não existiu jamais uma obra de arte na história humana que tenha sido puramente progressiva ou revolucionária, e que não tenha incorporado alguma forma de cumplicidade com o poder dominante". ${ }^{2} \mathrm{E}$ um texto como Orientalism constitui uma detalhada análise de uma história cultural que, dos gregos ao presente, apresenta como saber civilizatório sobre o Oriente o que é, na verdade, um discurso de exclusão e controle da alteridade que prepara o terreno para a dominação imperialista.

Said e Jameson diferem, contudo, na forma como denunciam a cultura "civilizatória" da violência. Trata-se de uma diferença intimamente ligada aos projetos individuais desenvolvidos pelos dois teóricos a partir de um confronto com teorias pós-estruturalistas. Enquanto para Said a verdadeira crítica depende da relativa independência da voz individual do crítico/intelectual que tenta resistir aos chamados tanto da cultura como dos sistemas corporativos, com a finalidade de aproximar-se mais da experiência histórica imediata, para Jameson

1. BENJAMIN, 1969. р. 256.

2. JAMESON, 1981. p. 10. a crítica é precisamente a voz que fala a partir de um sistema definido como horizonte último do conhecimento histórico. Os resultados diversos de tais percursos críticos alternativos tornam-se claramente visíveis no tratamento dado pelos dois críticos ao problema do poder opressivo globalizante. Como esses dois percursos resultam em propostas metodológicas fundadoras a serem exploradas por novas gerações de críticos culturais (Spivak, Homi Bhabha, ou Peter Hulme no caso de Said, Aijaz Ahmad no caso de Jameson) vale a pena tentar compreendê-los em suas linhas gerais.

A proposta de trabalho apresentada por Jameson em The Political Unconscious define o processo de interpretação de textos culturais como "essencialmente um ato alegórico, que consiste em rescrever um dado texto em termos de um código interpretativo dominante e específico". Sendo o código interpretativo dominante a história na perspectiva marxista (um relato único e final), o texto deve de alguma forma acomodar-se a ela ao ser traduzido em termos de suas regras. $O$ tex to é, finalmente, aquilo que o relato histórico único produziu e que não poderia produzir de outra forma, ou em outro estilo. Jameson descreve o processo de tradução do texto para o código mestre em termos da expansão em círculos concêntricos a partir de um centro constituído pelos "dados e materiais inertes de um texto particular". ${ }^{3}$ Note-se que, como lembrou Samuel Weber, um texto "cuja particularidade coincide com a sua inércia" é um texto situado "de uma vez por todas no seu lugar próprio dentro da história, vale dizer, em um relato que espera para ser dito de uma vez por todas e de uma única maneira". É preciso lembrar sempre o caráter fundamentalmente teleológico, ainda que aberto, de tal história: "como o movimento do próprio Capital, esse relato nunca termina, mas o seu desfecho está sempre à vista". ${ }^{4}$ A expansão a partir do tex to até o momento em que ele se reconhece como história ocorre pela progressiva contextualização textual na estrutura de eventos mais imediatamente "simbólica" e "política", seguida por uma contextualização mais ampla e no nível do "social" e chegando finalmente à contextualização mais abrangente, no nível do "histórico". 5

Nesse processo de contextualização, o tex to se revela previsivelmente como a manifestação concreta de um estilo, compreensível em termos de certos estágios na luta de classes ou no movimento do capital. O realismo, o modernismo e o pós-modernismo são estilos culturais que correspondem, 
respectivamente, ao capitalismo de mercado, ao capitalismo de monopólio, e ao capitalismo multinacional, ou capitalismo tardio. Esse último estágio de expansão do capital é caracterizado pela transformação em bens de consumo de praticamente todos os espaços, não apenas da vida social, mas também da vida pessoal: todas as formas de conhecimento e de informação, todas as experiências humanas, as experiências do inconsciente, inclusive, foram submetidas a um processo de reificação que as transformou em imagens desprovidas de referencial (já que o processo de reificação está completo) e disponíveis no mercado. "O pós-modernismo", diz Jameson, "é o que se tem quando o processo de modernização se completou e a natureza desapareceu de vez", já que "a totalidade da vida social — desde o valor econômico e o poder estatal até as práticas e a própria estrutura psicológicas" se tornaram "fatos de cultura". " Marcado pela proliferação incontida de imagens fragmentárias e sem história em uma vasta superfície desprovida de profundidade, o mundo pósmoderno tende a abolir distinções entre o sagrado e o profano, a cultura de elite e a cultura de massas, e a decretar o fim do indivíduo e do "eu" profundo na dimensão basicamente espacial de um eterno presente feito apenas de fragmentos do passado. Estes são agora desprovidos de memória histórica específica e de um futuro marcado por diferenças. Trata-se do mundo solicitado pelos imperativos do capital, que, em sua necessidade de expansão, produz fragmentações, atomizações, perda de memória histórica, dessacralizações. E trata-se, finalmente, de um mundo que, em sua vasta fragmentação, já não pode ser visto em sua totalidade por uma perspectiva crítica e nem ser mapeado justamente quando mais se torna necessária a prática crítica de produzir "mapas cognitivos" ("cognitive mappings").

Ao propor, da perspectiva totalizante de uma história única, o íntimo relacionamento entre o estilo pós-moderno e o movimento globalizante do capital, Jameson tem muito a dizer sobre pós-modernismo e poder opressivo em um nível global, e muito a dizer sobre as formas de criticar tal poder opressivo, inclusive propondo a reformulação de disciplinas tradicionais como a Literatura Comparada. É que a cultura pós-moderna, enquanto ligada ao movimento do capital multinacional, é ao mesmo tempo "global" e "norteamericana", e traz consigo "uma nova onda de dominação militar e econômica norte-americana no mundo todo". ' Como explica Jameson em ensaio recente, o capitalismo, em seu movimento expansivo na transformação do mundo em bem de consumo, sempre ocorre a partir de um centro, "cada novo centro sendo

6. JAMESON, 1991, IX, 48.

7. JAMESON, 1991. p.5. espacialmente mais amplo e mais inclusivo do que os centros precedentes." A partir do século XVIII, o capitalismo avança de seu momento nacionalista na Inglaterra da revolução industrial para o seu momento imperialista, ainda centralizado na Inglaterra do século XIX, e marcado pela expansão do mercado nacional e pelo estabelecimento de um sistema colonialista de alcance mundial. Migra a seguir para o seu novo centro, os Estados Unidos, e gradualmente substitui, particularmente após a Segunda Guerra Mundial, o sistema colonial pelo sistema das corporações multinacionais. O momento presente é ainda o do capital multinacional, com seu centro sendo agora novamente alterado e mantido "em difícil equilíbrio (após o desaparecimento da União Soviética) entre os três espaços centrais da Europa, dos Estados unidos, e do Japão, cada um com suas imensas periferias de estados satélites" .80 capitalismo pós-moderno, ao mesmo tempo global e heterogêneo, produz diferenças e desigualdades entre centros em expansão e suas periferias dominadas, estas últimas marcadas com particular intensidade no presente momento pelos efeitos sociais do "permanente desemprego estrutural, da especulação financeira e do movimento ingovernável do capital."

Apesar da dificuldade, essa onda de dominação deve ser, de alguma forma, mapeada em seus aspectos dialéticos de catástrofe e progresso, embora esse mapeamento seja impossível, porque a fragmentação pós-moderna não se presta ao procedimento totalizante que é parte necessária de todo ato de mapear; é, contudo, necessário, porque a ausência de conceitos totalizantes implica na paralisia, na confusão e no silêncio do crítico diante da multiplicidade incontrolável. Jameson produz um tal mapeamento ao conceitualizar o pósmoderno enquanto "dominante cultural". Em suas palavras, "a menos que se obtenha uma noção genérica de dominante cultural, regride-se para a perspectiva da história do presente enquanto pura heterogeneidade, diferença caótica, coexistência de uma multiplicidade de forças dispersas que não permitem escolha mais ou menos eficaz". ${ }^{10}$ Quando se tem a concepção de uma dominante cultural ou de uma norma hegemônica, "é possível medir e avaliar as diferenças [...]. O pós-moderno [...] é um campo de força no qual tipos diferentes de impulsos culturais - o que Raymond Williams denominou formas 'residuais' $\mathrm{e}$ 'emergentes' de produção cultural — necessitam abrir caminho"." É claro que há sempre dificuldades, algumas das quais insuperáveis, nessa tentativa de

\footnotetext{
8. JAMESON, 1996. p.2.

9.JAMESON, 1996. p. 10

10. JAMESON, 1991. p.6.

11. loc. cit.
} 
controlar diferenças por meio de uma lógica e de um modelo dominante porque a própria lógica em questão (a lógica do capitalismo tardio) "é dispersiva e desestruturante [...] e não apresenta movimento em direção a totalidades de quaisquer espécies". ${ }^{2}$ No entanto, e nisso Jameson aproxima-se de Said, não resta ao teórico preocupado com mudanças no status quo outra alternativa senão estabelecer centros de controle que venham a permitir a leitura de diferenças, subordinações, e exercícios de poder opressivo. Torna-se necessário produzir o mapeamento que estabelece, na lógica global do capital pós-moderno, diferenças entre centros e periferias em um espaço geográfico, ainda que com tal procedimento não se dê conta de forma satisfatória das diferenças internas dos espaços centrais e periféricos (diferenças raciais ou de gênero, por exemplo) e ainda que, como percebeu Aijaz Ahmad, tal mapeamento compartimente e torne homogêneos vastos espaços culturais que acabam por ter sua variedade $\mathrm{e}$ especificidade negadas.

A prática discursiva Jamesoneana de tentar perceber diferenças globais, mas sempre em relação a um sistema, produz, apesar das dificuldades metodológicas, contribuições para (e questionamentos certeiros de) certas disciplinas e formas de conhecimento. Jameson tem muito a dizer, por exemplo, sobre o significado de estudos comparativos globais no contexto pós-moderno. Se o pós-modernismo é, na realidade, a manifestação cultural de uma certa lógica do capitalismo tardio, uma lógica que privilegia "a pura heterogeneidade", a "diferença caótica" e a "coexistência de uma multiplicidade de forças dispersas que não permitem escolha mais ou menos eficaz", e se essa lógica tem um centro e uma periferia, é evidente que a força dispersiva atua mais no centro do que na periferia. Essa lógica fragmentária tende cada vez mais, como se viu, a tornar impossível toda distância crítica e atividade mapeadora na medida que se expande em dimensão global. "A prodigiosa expansão do capital multinacional", diz Jameson, "acaba por penetrar e colonizar até mesmo aqueles bolsões pré-capitalistas (a Natureza e o Inconsciente) que ofereciam pontos de apoio extraterritoriais e arquimedeanos para a ação crítica eficaz". ${ }^{13}$ No presente momento, contudo, os bolsões e as forças residuais existem ainda e tem valor particularmente importante na medida em que constituem exemplos de resistência ao processo hegemônico, que tende a eliminar toda ação crítica e toda intervenção na História. As literaturas do Terceiro Mundo enquanto alegorias políticas representam, para Jameson, exemplos desses bolsões de resistência, daí o seu valor e a necessidade de torná-las visíveis e, principalmente,

12. JAMESON, 1991. p. 100

13. JAMESON, 1991. p.IX.

de integrá-las no estudo do sistema maior de uma História totalizante.

Em "Third World Literature", Jameson entende as "alegorias nacionais" do Terceiro Mundo como exemplos de mapas cognitivos que representam a nação na medida em que revelam o lugar do indivíduo no contexto social e político. Essa possibilidade de mapeamento do espaço é ainda possível porque a periferia das classes dominadas é o espaço dialético oposto ao dos centros pós-modernos, nos quais o mapeamento é difícil ou impossível. Enquanto práticas políticas mapeadoras que já não existem no Primeiro Mundo, as literaturas do Terceiro Mundo constituem formas de conhecimento capazes de relativizar e enriquecer o contexto cultural pós-moderno primeiro-mundista. Reconhecer tais formas enriquecedoras de conhecimento seria a função primária de uma disciplina verdadeiramente capaz de dedicar-se a um "internacionalismo das situações nacionais"..$^{14} \mathrm{Em}$ uma tal disciplina, artefatos e práticas culturais africanas, caribenhas, ou brasileiras teriam não apenas um valor intrínseco como mapeamentos de regiões culturais específicas do Terceiro Mundo, mas também em outras regiões (inclusive as primeiro-mundistas) enquanto reveladoras "da dinâmica de dependência e resistência, exploração e desenvolvimento interno" "15 A recíproca, ou seja, a validade de artefatos primeiro-mundistas no Terceiro Mundo, deveria também ocorrer no contexto de uma tal disciplina desde que ela pudesse realmente se desenvolver fora da academia dos centros desenvolvidos, mas essa possibilidade não chega a concretizar-se na prática. É que a disciplina, por excelência, que deveria promover o "internacionalismo das situações nacionais", ou seja, a Literatura Comparada, por motivos tanto práticos e econômicos quanto políticos, não tem conseguido dar o salto do nacional para o internacional. O que Jameson tem a dizer em "The State of the Subject" ajuda a entender o problema.

A Literatura Comparada tentou no passado e tenta no presente legitimar-se como disciplina ao apresentar-se como um conjunto de estratégias teóricas (rejeição dos conceitos de fonte e influência, afirmação do conceito de intertextualidade) capazes de superar os esquemas teóricos confirmadores do conceito de nacionalidade, seja ela francesa, inglesa, brasileira ou outra qualquer. Jameson lembra, entretanto (e aqui se percebe uma das vantagens de uma perspectiva histórica globalizante), que, como disciplina acadêmica, a Literatura Comparada como disciplina acadêmica avança de forma paralela a certos movimentos do capital, que vai aos poucos constituindo, historicamente, o estado

\section{JAMESON, 1987b. p.22.}

15. JAMESON, op.cit. p.23 
nacional como preparação para o imperialismo global. Assim, a Literatura Comparada floresce na esteira de movimentos culturais transnacionais como o romantismo, que coincide historicamente com o período revolucionário burguês instaurador de nacionalidades e também com a inauguração de um novo imperialismo global: a colonização britânica da Índia, a invasão do Egito por Napoleão. Em um gesto tipicamente benjaminiano ("não existe ato civilizatório que não seja ao mesmo tempo um ato de barbárie"), Jameson vai lembrando que tais atos de violência imperialista coincidem, não por acaso, com a "descoberta do sânscrito por Sir William Jones em 1786" e a decifração do código hieroglífico por Champollion em $1799 .{ }^{16} \mathrm{E}$ não é igualmente por acaso que, no mesmo momento histórico, Goethe cunhe o termo "Literatura Universal" e produza uma obra marcada por um intenso interesse em outras culturas, o que o leva a traduzir textos árabes e pérsicos e a estudar com certa assiduidade dramas em sânscrito. Note-se que os comentários de Jameson o aproximam novamente da obra de Said na medida em que situam genericamente a cultura no contexto do projeto imperial, muito embora seja na obra de Said que, como se verá, serão estudadas as estratégias discursivas específicas de cujo uso tal situação ocorre. O discurso imperialista de Goethe, conforme apresentado por Jameson, pratica o "orientalismo" explicitado por Said, mas em contexto diverso. Enquanto Jameson vê o discurso imperialista de Goethe como resultado de um certo sistema econômico em sua dinâmica expansiva, Said entende o "discurso colonial" como parte de uma vasta produção discursiva cuja origem se encontra dispersa em varias instituições sociais de poder, e não simplesmente em uma história única.

Seja como for, Jameson apresenta um Goethe praticando certos ideais de Literatura Comparada muito semelhantes aos de futuros teóricos da área. Para Jameson, o significado da "Literatura Universal" em Goethe "era algo como o conceito contemporâneo de meios de comunicação (mídia), particularmente na forma como grupos de intelectuais, através de jornais e periódicos, influenciariam e tornariam interligadas as obras dos produtores de culturas e escritores além das fronteiras nacionais". O projeto de Goethe, acrescenta Jameson, embora sem sucesso no passado (e, como se verá, ainda sem sucesso na Literatura Comparada dos nossos dias), permanece tão urgente hoje como nos tempos de Goethe; talvez até mais urgente:

Como muitos outros aspectos do Iluminismo burguês, esse ideal "utópico" de Goethe nunca se concretizou, quer na vida intelectual, quer no

16. JAMESON, Op.cit. p. 17 desenvolvimento do sistema educacional. Permanece vital e estimulante hoje, quando uma das novas tarefas do sistema universitário no Primeiro Mundo é justamente ir ao encontro da nova e imensa riqueza das culturas e literaturas do Terceiro Mundo, e quando, para o bem ou para o mal, a unificação do planeta é mais real do que no tempo de Goethe. ${ }^{17}$

Não seria difícil constatar como o ideal Goetheano continua presente entre os praticantes da Literatura Comparada. Para François Jost, por exemplo, "o esforço e a recompensa do comparatista consiste em perceber o universo literário em sua unidade fundamental"lı E, para Owen Aldridge, "a Literatura Comparada pode ser vista como o estudo de qualquer fenômeno literário do ponto de vista de mais de uma literatura nacional ou em conexão com outra, ou mesmo várias disciplinas intelectuais". ${ }^{19}$ Para que o ideal totalizante de ultrapassar fronteiras se torne possível, é indispensável o pressuposto da unidade mais limitada da nação, que, como Jameson sugere, não é apenas uma naçãocultura ou uma nacão-literatura em seus afazeres estéticos com o objetivo idealizante e totalizador de atingir uma "unidade fundamental". São, ambas, partes inseparáveis do estado-nação e das forças que o constituíram. Nesse contexto, a Literatura Comparada acaba por legitimar a nação no próprio movimento de tentar ultrapassar as suas fronteiras. Tal procedimento parece ser ainda mais verdadeiro no Terceiro Mundo, onde, em alguns casos, parece até mesmo ser possível relegar a segundo ou terceiro plano o internacional para que se enfatize, a todo custo, o nacional. Como mostrou recentemente Susan Bassnet, o que marca a Literatura Comparada praticada "fora da Europa e dos Estados Unidos" é antes a "necessidade de começar com a cultura doméstica e depois olhar para fora, que começar com o modelo europeu de excelência literária e depois olhar para dentro". A Associação Indiana de Literatura Comparada, por exemplo, colocou como seu principal objetivo "atingir uma concepção da literatura indiana capaz não apenas de modernizar os departamentos de literatura, mas também de dedicar-se à revelação da grandeza da literatura indiana e apresentar uma visão panorâmica de sua atividade literária através dos tempos."20 O contexto ideológico em que hoje se desenvolvem as atividades de Literatura Comparada no Brasil não é certamente muito diverso. Tudo se passa como se a Literatura Comparada terceiro-mundista tentasse utilizar a Literatura Comparada
17. JAMESON, op.cit. p.17.
18. JOST, 1974. p. IX.
19. ALDRIDGE, 1969. p.I.
20. BASSNET, 1993. р.38-39. 
para praticar o que esta sempre tentou evitar mas nunca conseguiu: a legitimação do nacional.

É claro que é sempre possível tentar atenuar essa ênfase no nacional por meio de um deslocamento de foco que venha a privilegiar uma outra dimensão supostamente comparável do texto que não a da nacionalidade. $\mathrm{A}$ dimensão estética apresenta-se logo como tábua de salvação capaz de interligar produções textuais em uma unidade maior. "A Literatura Comparada no presente momento", diz Peter Brooks, "afirma sua especificidade e sua razão de ser ao formular, de forma sempre renovada e multivalente, a pergunta a respeito do que é a literatura e o que significa estudar literatura". Indagar sobre a essência da literatura significa, em resumo, indagar sobre a sua estética e sua literariedade enquanto realidades auto-suficientes a serem isoladas de outros contextos. Brooks endossa sem qualificações a perspectiva de Michel Riffaterre, para quem um texto "é literário na medida em que sobrevive ao esgotamento dos problemas, ao desaparecimento das causas, e à memória das circunstâncias às quais ele respondeu"." O problema é que, nesse contexto, escapa-se do nacional para cair em formas trans-históricas com as quais dificilmente se pode, hoje, conviver sem indagar sobre as possíveis razões que levam à escolha de tal convívio, e sobre as maneira pelas quais uma tal fuga para o estético convenientemente esquece sua capacidade de legitimar exercícios de poder além do estético.

A Literatura Comparada parece, assim, condenada a uma crise perpétua, porque tentar evitar o nacional é arriscado e, por outro lado, permanecer como forma de legitimação do nacional é pouco satisfatório, e não apenas pelas conexões perigosas com o estado nacional. Como lembra Jameson, a ênfase no nacional traz consigo o problema do cânone, o problema da especialização, e o problema de uma categoria definidora de fronteiras que perde cada vez mais sua validade teórica e prática em um mundo globalizado. Assim, o relacionamento com a literatura nacional enquanto lista canônica de autores e obras mostra-se problemático em um momento histórico em que se torna cada vez mais difícil a possibilidade de se pensar o canônico como "natural", evidente, ou consensual, e se pergunta cada vez mais insistentemente, como, por que regras, e com que interesses se fabrica arbitrariamente um cânone. Por outro lado, as áreas canônicas nacionais não são, hoje, o que eram em estágios anteriores da Literatura Comparada como disciplina. Áreas canônicas mais vastas não apenas se tornaram áreas de especialização, como também se fragmentaram em áreas menores ainda mais especializadas. Essa especialização

21. BROOKS, 1995. p. 104, 103. crescente traz consigo indagações sobre quem pode legitimamente falar sobre áreas específicas, o que provoca em muitos praticantes da Literatura Comparada a "angústia da competência". Para que efetivamente se possa comparar duas ou mais culturas ou literaturas em sua complexidade, que conhecimento específico é necessário se não se quer cair em uma "interdisciplinaridade" que seja mero diletantismo? É possível praticar Literatura Comparada utilizando traduções? Se a tentação é grande para se tentar "perceber o universo literário em sua unidade", há um risco também grande de se falar do que não se sabe, o que parece ser ainda um pecado capital em certas áreas acadêmicas. Aijaz Ahmad caracterizou recentemente certas variedades de "literatura universal" no contexto acadêmico da universidade americana como "charlatanismo bem-intencionado":

Conheço pessoalmente várias pessoas cujo conhecimento do Sul asiático é, na melhor das hipóteses, lamentável, mas que se sentem perfeitamente autorizadas a dar cursos de pós-graduação cheios de romances sobre o Sul asiático, em universidades onde professores com níveis comparáveis de ignorância sobre a história social norte-americana jamais seriam autorizados a falar de Melville, ou de Henry James. Há um pressuposto apressado aqui de que o que está em jogo é um conjunto de artefatos culturais de densidade menor, e que não é necessário, portanto, muita competência para explicá-los, ou de que boas intenções são suficientes para resgatar a ignorância. O que é de se lamentar, em outras palavras, é que aqui se está tratando a idéia de Literatura Universal mais como um imperativo moral, e que o imperativo é vivenciado frequientemente de uma forma simplificadora e simplória. Isso não quer dizer que aqueles que ensinam sua literatura nacional - por exemplo, os que ensinam Melville ou James - são em sua totalidade pessoas bem-informadas ou eruditas. No entanto, e de forma geral, algumas regras sobre a leitura bem-informada estão consolidadas. No momento, tais normas não se aplicam à Literatura Universal. ${ }^{22}$

Problemas de listas canônicas e de "angústia de competência", contudo, talvez não sejam tão significativos quanto o problema da ênfase do nacional em um contexto de globalização. A perspectiva comparatista, ao propor a possibilidade de justapor textos ou fenômenos distantes histórica e geograficamente, e desprovidos de uma relação imediata de continuidade,

22. AHMAD, 1995. p.52. 
considera essas realidades distantes e diversas como versões de uma mesma estrutura, sem o que não seriam comparáveis. A proposta acaba por gerar, como percebe Jameson, "uma contradição fundamental [...] entre cronologia e modelos [...] entre história e sociologia, entre o diacrônico e o sincrônico, entre fatos e teoria [...]." ${ }^{23}$ É possível tentar resolver a contradição se se enfatizar, alternadamente, uma das polaridades em detrimento da outra. Pode-se, por exemplo, examinar certos tipos de representação realistas em mais de um contexto, deixando para trás "a perspectiva [...] de continuidade histórica", para enfatizar "alguma coisa suspeitosamente análoga a formas trans-históricas," de tal forma que "a própria História se transforme em um imenso laboratório nãohistórico, cujos vários momentos dispersos se assemelham a experimentos científicos separados". ${ }^{24}$ Ou pode-se enfatizar o contexto histórico examinandose, por exemplo, o relacionamento entre "um naturalismo ou realismo emergente - a representação social e visual da realidade concreta, a valorização da versossimilhança, mas também a conquista das técnicas pelas quais se obtém a representação realista" e o "aparecimento de uma economia comercial", o que daria margem a indagações sobre o relacionamento entre mudança econômica e mudança em formas artísticas e culturais. ${ }^{25}$ Existem, nos dois casos, problemas diversos a serem enfrentados: o desconforto, no primeiro caso, de recorrer a formas trans-históricas; e, no segundo caso, o da incerteza sobre quais fatos históricos utilizar diante do acúmulo de evidência histórica em uma dada tradição. No entanto, dado o fenômeno da globalização no presente momento, a ênfase trans-histórica em formas de "experimentos científicos" a serem examinados contrastivamente complica-se ainda mais, uma vez que a presença de um sistema geral de contaminação de culturas espalha "influências" por toda a parte. Com o advento da cultural global, do capitalismo e do imperialismo, o estudo, por exemplo, do "realismo" em sociedades diversas já não é mais possível em "condições de laboratório":

Nesse momento histórico, a questão da influência cultural (ou mesmo a da dominação cultural) intervém para complicar a investigação: na realidade, na medida em que a unificação avança rapidamente em nossos dias, acelerada pelos meios de comunicação de massa (que garantem, por exemplo, que qualquer trabalhador agrícola do Terceiro Mundo seja exposto, em maior ou menor escala, a formas de cultura norte-

23. JAMESON, 1987b. p. 22 .

24. JAMESON, 1987b. p.2i.

25. JAMESON, 1987b. p.21. americanas), esses tipos de comparação tendem a parecer antiquados, e a História retorna em uma forma nova e dialética, como a História de todas estas diversas Histórias locais, e como a unificação dialética de uma grande variedade de processos locais semi-autônomos. Nesse caso, contudo, os estudos comparativos literários e culturais teriam que dar lugar a um novo tipo de disciplina organizado ao redor do fenômeno central do "imperialismo cultural".

É impossível, mais uma vez, deixar de notar a ênfase totalizante em Jameson, nesse caso, em relação a uma nova perspectiva da Literatura Comparada, agora redefinida para tonar-se realmente capaz de transcender o local e o nacional e recolocá-los em um contexto global. Nessa nova disciplina (que viria ao encontro da presença de uma globalização não apenas utopicamente desejada, como em Goethe, mas inevitável como fato provocado pelo capital), "as nações européias e suas literaturas nacionais seriam percebidas apenas como variantes estruturais do desenvolvimento do capitalismo nacional" e as culturas coloniais e pós-coloniais seriam exemplos "da dinâmica de dependência e resistência, exploração e desenvolvimento interno." O problema central a ser atacado pela nova disciplina seria, na verdade, o próprio fenômeno do capitalismo global como força centralizadora que produz centros e periferias, formas de acomodação e formas de resistência. E a ênfase dos estudos culturais e literários na nova disciplina recairia não tanto nos textos ou discursos culturais em si, mas em sua situação enquanto resposta aos (ou tentativa de solução dos) problemas e contradições existentes no sistema cultural local ou nacional em seu todo e como diferença em relação ao sistema global. Definidas duas ou mais situações locais ou nacionais em seus contextos conflituosos de ordem política e histórica, tais situações poderiam, então, ser comparadas tanto entre si como em relação à força globalizante do capital. Tais estudos revelariam, evidentemente, as diferenças locais determinadas pelo movimento do capital em suas centralizações/descentralizações: "a cultura mexicana enfrenta problemas diversos da venezuelana, e a cultura da Inglaterra da Era Thatcher tem problemas diferentes dos da República Federal da Alemanha," e todos esses, por sua vez, constituem situações diversas quando comparados a um super-Estado como os "Estados Unidos", que não têm uma cultura nacional no sentido que outros países a têm. ${ }^{27}$

26. JAMESON, 1987b. p.22.

27. JAMESON, 1987b. p.24.
Disponível em http://www.letras.ufmg.br/poslit
REVISTA DE ESTUDOS DE LITERATURA Belo Horizonte, v. 5, p. $17-38$, out. 97 
Jameson propõe caracterizar a nova disciplina como um "internacionalismo das situações nacionais." É claro que tal área de estudos não se desenvolveria sem problemas, e Jameson tem consciência deles. Permanece, dado um tal campo de abrangência, o problema de níveis de competência mencionado anteriormente por Ahmad, e em particular o problema do conhecimento lingüístico, já que "a produção das literaturas não-ocidentais é com frequiência marcada por questões de linguagem e muitas vezes voltada para problemas de reforma e revolução da língua." Como normalmente não se espera do acadêmico ocidental que conheça línguas não-ocidentais, permanece o problema de quem tem autoridade para praticar uma disciplina de âmbito globalizante. Jameson afirma, contudo, a necessidade de sua existência e desenvolvimento, se não por outro motivo, pelo menos porque só com ela se tornará possível realmente relativizar toda e qualquer cultura e "evitar a paroquialização das antigas literaturas nacionais e a incorporação, no trabalho tanto de alunos como de professores, de tex tos de culturas radicalmente diversas. Enquanto tais culturas existirem em isolamento especializado [...], de forma que apenas sinologistas possam ensinar textos chineses, arabistas, textos de literaturas árabes modernas, e anglicistas, as literaturas em língua inglesa, não se tornará possível e nem mesmo concebível o campo da literatura global". ${ }^{28}$

Encontram-se em Jameson, portanto, tanto o diagnóstico de uma necessidade de estudos literários e culturais em âmbito global, como uma proposta de uma metodologia e de uma disciplina que deles possa dar conta. Mas, na medida em que, na proposta de Jameson, tal disciplina deve necessariamente recorrer ao ponto de vista da história marxista como o grande e único relato (o que permite, no final das contas, inserir o problema da luta de classes na disciplina da Literatura Comparada), a crítica que se pode fazer a tal proposta relaciona-se com a questão das possíveis limitações do marxismo em seu aspecto de sistema que propõe uma explicação histórica de alcance universalizante a partir de uma perspectiva eurocêntrica. Essa crítica pode ser melhor percebida quando se contrasta, ainda uma vez, a proposta de Jameson com a proposta alternativa de Edward Said.

Edward Said desenvolve em sua obra uma proposta de redefinição da crítica literária e cultural em termos da necessidade de reconstituir a conexão entre texto, mundo e História, para que se torne possível revelar o exercício sub-reptício de poder mundano no âmbito do discurso e, nessa prática crítica, dizer a verdade ao poder textual e mundano onde quer que ele se encontre. Ao

28. JAMESON, 1987b. p.23 contrário do que ocorre em Jameson, contudo, essa atividade crítica de denúncia não deve jamais ser praticada a partir de um sistema ou de "ismos" de qualquer espécie mas sim a partir do crítico/intelectual situado em equilíbrio precário entre cultura e sistema e de sua crença em valores universais de igual direito à dignidade, à justiça e a um mínimo de cidadania para todos os seres humanos. Para Said, a ênfase na postura crítica individual teria a vantagem de, ao mesmo tempo, aproximá-la da experiência histórica imediata e concreta e tornar possível maior flexibilidade e amplitude, para que a sua voz pudesse dirigir-se a problemas não cobertos pelos "ismos". A essas áreas não cobertas pelos "ismos" oficiais, Said dá o nome genérico não de "capitalismo", mas de "imperialismo":

O que ler e o que fazer com a leitura, essa é a forma genérica da questão. Toda a energia dedicada à teoria crítica, à ficção e à práticas teóricas desmistificadoras como a Nova História, o Desconstrucionismo e o Marxismo se esquivaram daquilo que é o horizonte maior, e eu diria até mesmo determinante, da cultura ocidental moderna, ou seja, o imperialismo. ${ }^{29}$

Em Culture and Imperialism (1993), Said tenta mostrar a presença insistente do conceito de "imperialismo" na cultura ocidental apontando para as suas variadas manifestações históricas, suas conexões com a produção cultural e seus efeitos em práticas colonizadoras. Definido de forma genérica, o imperialismo é aquela prática de violência que se encontra permanentemente presente, e em múltiplas dimensões, na "totalidade do devir histórico e secular humano":

O imperialismo, enquanto fato inseparável de suas dimensões culturais básicas, é tão vasto e ainda assim tão particularizante que é preciso falar dele além de domínios territoriais, enquanto histórias entrelaçadas de homens e mulheres comuns, brancos e negros, habitantes das metrópoles e das periferias, no passado tanto quanto no presente. Esses territórios e essas histórias podem apenas ser compreendidos a partir da perspectiva da totalidade da história secular humana. ${ }^{30}$

Note-se, em Said, que a "totalidade da história secular humana" é tão

\section{SAID, 1993. p.70.}

30. SAID, 1993, p.72. 
totalizante quanto o conceito de história definido por Jameson como "uma única narrativa vasta e incompleta" ${ }^{31}$. No entanto, em Said, essa totalidade vista em sua persistente prática imperialista alcança um nível de detalhamento que seria dificilmente possível na perspectiva macroestrutural marxista. Said, por assim dizer, quer estender sua fala de crítico e intelectual a problemas tanto macro como microestruturais, e precisa de um conceito instrumental mais flexível do que o de "capitalismo" ou "luta de classes". O conceito operatório de "imperialismo" permite, por exemplo, que não se coloque em primeiro plano formas de resistência em sua dimensão social e de luta de classes, o que relegaria a segundo plano as histórias particulares de "homens e mulheres comuns". Estas últimas são partes inseparáveis do projeto imperialista ao qual tentam oferecer resistência não necessariamente como classe. Em Culture and Imperialism, Said tenta insistentemente definir, por vezes de forma genérica, a amplitude de tal projeto e a violência de seus efeitos nos espaços colonizados. $\mathrm{O}$ projeto imperial é apresentado no livro, ora em termos de seu interesse em explorar o outro colonizado, agindo sobre "as fundações geográficas, espaciais e territoriais da vida social", ora em termos de suas ambições mais especificamente territoriais, como no caso da prática de "pensar sobre, estabelecer-se em, e controlar a terra que não se possui e que está distante, habitada e possuída por outros".

Vale a pena destacar, nesta última definição, a ênfase atribuída à atividade de "pensar sobre" a terra a ser colonizada, já que tal ênfase leva de saída a pensar a cultura e, mais especificamente, à leitura de textos em âmbito tanto nacional como internacional (vale dizer, a leitura proposta pela Literatura Comparada), e isso em termos marcadamente diversos das propostas de Jameson. Enquanto para Jameson, como se viu, um texto existe em termos de "dados e materiais inertes" 33 a serem alegoricamente reescritos em termos do código dominante da história única marxista, para Said o texto imperial é justamente aquele "pensar sobre" cultural que freqüentemente ativa, prepara e dinamiza o projeto imperialista. Longe de ser apenas programado por um código mestre, o texto programa e mapeia com antecedência o processo de colonização e, posteriormente, acompanha e incentiva a dominação imperial com o desenvolvimento de novas formas discursivas. É nesse sentido que Said, leitor atento de Joseph Conrad e, em particular, de Heart of Darkness, percebe que o "projeto imperial depende da idéia de ter um império [...] e ativam-se [para

\section{JAMESON, 1981. p.19-20.}

32. SAID, 1993. p.57, 5

33. JAMESON, 1981. p. 19 . tanto] variados tipos de preparação". ${ }^{34}$ Textos como Orientalism e Culture and Imperialism (que seriam, sem dúvida, melhor compreendidos quando lidos como textos complementares) constituem, de formas diversas, estudos dedicados a formas culturais que tomam esses "variados tipos de preparação" enquanto configurações ideológicas complexas subjacentes à "tendência ao imperialismo". 35

Culture and Imperialism, diz Said, constitui um estudo dedicado àquele "relacionamento geral entre cultura e império que se tornou patente para mim enquanto escrevia Orientalism". ${ }^{36}$ Como Jameson, Said insiste na inseparabilidade entre civilização e barbárie percebida por Walter Benjamim. Ao contrário do que ocorre em Jameson, porém, o texto cultural não é, aqui, Ao contrário do que oxperiência apenas material ina", marcada por combates não apenas "de soldados e canhões, imperial moderna", máas, formas, imagens e formas imaginárias". ${ }^{37}$ Daí a mas também de idéias, formas, imagens e formas imaginarias" "o imaginário do império":

É preciso investigar tanto a nostalgia do império quanto a ira e o ressentimento por ela provocados nos oprimidos, e olhar atenta e exaustivamente a cultura que nutriu o sentimento, a racionalidade e, sobretudo, o imaginário imperial. E é preciso tentar ainda compreender a hegemonia da ideologia imperial, que no final do século XIX integrouse completamente às questões culturais cujos aspectos menos danosos são até hoje celebrados. ${ }^{38}$

Colocar a cultura como centro da atenção crítica e nela tentar perceber - "imaginário do império" e de seus efeitos no processo de colonização é o objetivo principal de Said tanto em Orientalism como em Culture and Imperialim. Tomados em conjunto, os dois textos representam um esforço para estabelecer possiveis direcionamentos gerais em um estudo interdisciplinar de textos enquanto "discursos coloniais". Influenciado por Foucault, Said entende por discurso não apenas um conjunto ou constelação de textos relativamente
34. SAID, 1993. p. 10.
35. SAID, 1993. p.82
36. SAID, 1993. p.XI.
37. SAID, 1993. p. 3,6
38. SAID, 1993. p.12.

REVISTA DE ESTUDOS DE LITERATURA

Belo Horizonte, v. 5, p. 11 - 38, out. 97 
autônomos e pertencentes a uma disciplina ou tradição, mas também tais textos quando organizados em termos de suas filiações institucionais e ideológicas e, portanto, enquanto práticas constituídas simultaneamente de saber e poder. Para Said, o grande mérito de Foucault foi ter tornado possível a "compreensão das formas pelas quais a vontade de exercer o controle dominante na sociedade e na História [...] ou a ganância para fazê-la inventar formas de se vestirem, disfarçarem e ocultarem sistematicamente no discurso da verdade, da disciplina, da racionalidade, do valor utilitário e do conhecimento." ${ }^{39}$ É este o conceito operatório usado para examinar, em Orientalism, "a disciplina prodigiosamente sistemática através da qual a cultura européia conseguiu controlar — e até mesmo produzir - o Oriente em termos sociológicos, militares, políticos, ideológicos, científicos e imaginários durante o período posterior ao Iluminismo." ${ }^{40} \mathrm{O}$ mesmo conceito está, ainda, presente em Culture and Imperialism, mas no tex to mais recente Said amplia o objeto de estudo. Enquanto o estudo interdisciplinar do discurso colonial limita-se, em Orientalism, ao Oriente Médio, Culture and Imperialism representa uma ampliação do foco analítico, agora dirigido para "um sistema genérico de cultura imperial espalhada globalmente, e para a experiência histórica de resistência contra o império." pela ênfase na "cultura imperial", a proposta de Said não difere da de Jameson, que também propõe um estudo interdisciplinar de alcance globalizante, mas com ênfase na expansão do capitalismo e na dominante cultural dele resultante.

Essa diversidade de ênfase entre a perspectiva marxista para o estudo do capitalismo e a análise do discurso aplicada à cultura imperial tem conseqüências importantes e aponta para uma diferença metodológica significativa entre os dois projetos. É possível melhor perceber essa diferença se retornarmos, por um momento, à apreciação crítica que Said faz de Foucault em "The Problem of Textuality". Said absorve de Foucault o conceito de discurso enquanto exercício de saber/poder, mas, ao mesmo tempo, acusa o filósofo francês de etnocentrismo ao chamar a atenção para a geografia européia implícita em uma obra que, sob outros pontos de vista, constitui justamente uma crítica ao exercício de poder europeu. Foucault, de acordo com Said,

não parece estar interessado no fato de que a história não se faz a partir de um território homogêneo francês [...]. Parece não perceber quão

\footnotetext{
39. SAID, 19780. p.705.

40. SAID, 1978b. p.3.

41. SAID, 1993. p. XII.
}

intensamente as idéias de discurso e disciplina são decididamente européias e como, juntamente com o uso da disciplina para a utilização de uma grande quantidade de detalhes (e de seres humanos), a disciplina era também usada para administrar, estudar, reconstruir - e em seguida ocupar, governar e explorar - a quase totalidade do mundo não-europeu. ${ }^{42}$

Foucault, em outras palavras, foi capaz de explicar luminosamente o funcionamento do poder, mas nada disse sobre o uso desse poder para a dominação de povos fora da Europa, o que, subentende-se, caberia ao próprio Said fazer em Orientalism e, mais tarde, em Culture and Imperialism. Mais uma vez, e ainda possivelmente na tentativa de utilizar Foucault para a consolidação de sua própria voz crítica, o comentário de Said peca por um certo exagero, já que Foucault, no prefácio de Histoire de la Folie, comenta sobre a oposição entre Oriente e Ocidente de forma muito semelhante ao próprio Said, e isso já em 1961. Como diz Foucault, "O Oriente é [para o Ocidente] tudo aquilo que o Ocidente não é, e o lugar onde o Ocidente deve procurar a sua verdade primitiva. Será necessário fazer uma história dessa grande linha divisória, persegui-la em suas continuidades e suas trocas, mas deixá-la também aparecer em sua trágica estilização". ${ }^{43}$ Como lembrou recentemente Peter Hulme, o comentário de Foucault "poderia muito bem servir como uma epígrafe para Orientalism".44

Apesar do exagero, a observação de Said sobre a geografia eurocêntrica da obra foucaultiana permanece válida e foi, de resto, admitida pelo próprio Foucault em entrevista concedida aos editores de um periódico de estudos geográficos. Indagado sobre a imprecisão do foco geográfico em sua obra ("suas áreas de referência são ora a cristandade, ora o mundo ocidental, ou a Europa ou a França, sem que tais espaços de referência sejam claramente justificados ou definidos com precisão"), Foucault acaba por reconhecer a necessidade do estudo de uma "geografia do poder"45, o que significa, em última análise, admitir as limitações eurocêntricas de sua obra, apesar do brilhante esforço nela feito para questionar o eurocentrismo no interior de suas próprias entranhas. Válida no caso da teoria de Foucault, a crítica de Said é igualmente aplicável à teoria marxista, e mais especificamente à obra marxista de Jameson,
42. SAID, 19780. p.710-711.
43. FOUCAULI, 1961. p. IV.
44. HULME, 1989. p.5.
45. FOUCAULI, 1976. p.67, 77 . 
já que esta pertence igualmente a uma certa geografia. A diferença é que Jameson, mais do que Foucault, interessa-se pela prática de uma crítica ao capitalismo em sua dimensão globalizante, e interessa-se não apenas pelo Oriente, como também pelo Terceiro Mundo como um todo. O problema é que, como percebeu Ahmad, tal interesse a partir de uma única História feita pelos poderes centrais dominantes acaba por reduzir a complexidade histórica do Terceiro Mundo a um efeito da História do centro, ainda que tal efeito se dê sob a forma de resistência manifestada em alegorias nacionais. No limite, a História do Terceiro Mundo reduz-se a um apêndice, a uma resposta previsível desencadeada pela opressão do movimento do capital a partir de seu centro primeiro-mundista. A questão da História do Terceiro Mundo enquanto essencialmente dependente do fazer histórico a partir do centro do capital, percebida por Ahmad, foi ainda mais agudamente criticada por Robert Young. Quando Jameson fala da "História em si", diz Young, o que é preciso indagar é a quem pertence tal História. E a resposta pode ser decepcionante para o Terceiro Mundo, na medida em que, como diz Young, é possível que "Jameson precise do Terceiro Mundo mais do que o Terceiro Mundo precisa dele":

Em resumo, a quem pertence a História freqüentemente denominada por Jameson como "a História em si"? Ninguém aparentemente possui uma História a não ser "nós" - ou seja, a civilização e a perspectiva ocidentais, que para Jameson parece significar os Estados Unidos. À sua maneira, esse projeto de resgate [da História] apenas repete a história do colonialismo europeu, da grande narrativa capitalista, na qual o mundo além das fronteiras européias, o seu outro, foi progressivamente integrado em seus impérios, com as culturas diversas menosprezadas e as outras Histórias negadas. Em "Third World Literature in the Era of Multinational Capitalism", Jameson descreve o Terceiro Mundo como uma entidade homogênea que pode ser definida apenas em termos de sua experiência colonial. Caracterizando toda a literatura do Terceiro Mundo como diversa daquela do Primeiro Mundo, mas essencialmente a mesma em sua diferença, Jameson define uma única maneira na qual ela deve ser lida, ao mesmo tempo que avisa a seus leitores: "Nada se ganha com o esquecimento silencioso da diferença radical dos textos não canônicos. A ficção do Terceiro Mundo não oferecerá as satisfações de Proust ou de Joyce"'4.

46. YOUNG, 1944. p.113-114.
Ainda que a contrapelo, Jameson trabalha com uma certa auto-imagem tradicionalmente característica da Europa e, mais recentemente, do "Ocidente". A essência dessa imagem reside na crença em uma diferença e um destino especiais que marcam o europeu e o ocidental em relação ao resto do mundo. Trata-se da diferença que situa seja a Europa, seja o Ocidente ou, mais recentemente, os Estados Unidos como modelo do futuro, a ser seguido pelo resto do mundo. Como lembrou recentemente Peter Hulme, a diferença especial é apresentada basicamente em termos de uma temporalidade que funda o relacionamento entre o Ocidente e seu outro em termos de atraso. Nesse contexto, o Ocidente produz para si uma autodefinição paradigmática em relação à qual o resto do mundo define-se como distância a ser compensada, sendo assim sempre "mais ou menos subdesenvolvido" e lutando permanentemente para atingir o desenvolvimento. Jameson trabalha nesse modelo, mas ao revés, na medida em que o reformula, por assim dizer, espacialmente, em uma tradição dialética bem conhecida. Um caso paradigmático dessa tradição, como lembra ainda Hulme, é o clássico de Eric Williams, Capitalism and Slavery (1944), que tenta "mostrar como o próprio capitalismo europeu moderno se constitui pelo lucro do tráfico escravocrata" e que a escravidão não pode ser simplesmente vista como um desvio perverso ocorrendo em um estágio particularmente dinâmico do progresso ocidental. Mais recentemente (e mais particularmente relevante para a compreensão de Jameson), a teoria do sistema global amplia a proposta de Williams ao tratar espacialmente os conceitos de centro e periferia como interdependentes, de forma que "o subdesenvolvimento das áreas periféricas, longe de ser o resultado de estruturas sociais arcaicas, é na realidade o produto de suas relações históricas com o mundo desenvolvido". ${ }^{47}$

Note-se que a espacialização dialética dos conceitos de centro e periferia como mutuamente dependentes questiona o modelo da centralização temporal do Ocidente (avanço/atraso), mas só o faz através de uma dialética entre centro e periferia na qual o fazer histórico continua centralizado, ou seja, a História pertence ao centro. A originalidade da obra de Said, e de Orientalism em particular, consiste em questionar essa centralidade histórica ao mostrar, pela ênfase na análise do discurso colonial, que a história cultural do Ocidente e de seus sistemas de conhecimento (inclusive o marxista) se constituiu, desde sempre, na forma de mecanismos repressores de outras Histórias que iam sendo apagadas ao serem reescritas. É nesse contextos que os orientalistas, produzindo um oriente para os europeus, apagavam o Oriente outro em sua multiplicidade

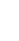


e complexidade. Para se reconhecer esse apagamento da alteridade, torna-se necessário, na medida do possível, o arastamento estratégico dos sistemas europeus de conhecimento, que, como se viu no caso de Foucault, dificilmente escapam de uma geografia eurocêntrica, mesmo quando reconhecem o problema. Em Said, escapar de tais sistemas significa tentar considerar, nem sempre com sucesso (como escapar daquilo que constitui o crítico como sujeito?), que a atividade crítica ocorre entre cultura e sistema, e não a partir de um sistema e da grande narrativa que o acompanha.

Cabe ao crítico/intelectual que opera entre cultura e sistema "iluminar fontes alternativas, desenterrar documentos ocultos, reativar Histórias esquecidas (ou abandonadas)". ${ }^{48}$ Mas como, por exemplo, "reativar Histórias esquecidas", se já são todas, de saída, contidas por um sistema que as situa em um relato único maior? Torna-se imperativo deslocar o foco de atenção da centralização de um sistema para a disseminação de um discurso no qual, a partir de uma perspectiva ética universalizante, centrada na dignidade do ser humano, tornese possível entrever as marcas do exercício de poder imperial. É essa a tarefa a ser realizada em Culture and Imperialism, pelo deslocamento de foco da economia e da luta de classes para a cultura e a prática do discurso colonial:

Minha intenção é examinar como o processo do imperialismo ocorreu além da dimensão das leis econômicas e das decisões políticas $\mathrm{e}-$ por predisposição, pela autoridade de formações culturais reconhecíveis, pela consolidação constante na educação, na literatura e nas artes musicais manifestou-se em uma outra dimensão muito importante, aquela da cultura nacional que temos tentado domesticar como o lugar dos imperecíveis monumentos intelectuais, livres de afiliações mundanas. ${ }^{49}$ (O grifo é meu.).

É claro que a tentativa de afastamento dos sistemas eurocêntricos pelo deslocamento de foco do sistema para o discurso cultural marcado pela presença opressiva do império só pode ter sucesso relativo. Afastar-se do contexto eurocêntrico a que se pertence e pelo qual se é constituído não é tarefa fácil. Ao fim e ao cabo, Said escapa de certas formas de eurocentrismo apenas para cair em outras, que foram de resto abundantemente denunciadas pela crítica. Orientalism, por exemplo, ao mesmo tempo que denuncia a história eurocêntrica que produziu o discurso do orientalismo, recorre a valores eurocêntricos e

\section{SAID, 1993. p.XV.}

49. SAID, 1993. p.12. humanistas tradicionais como uma forma de antídoto ao processo de dominação imperialista. Como mostra Aijaz Ahmad em contundente crítica ao livro, "após reconstituir a narrativa da literatura européia em seu todo, de Ésquilo até Edward Lane, como a história da cumplicidade do literário no processo de inferiorização do 'Oriente', e após identificar o racionalismo iluminista como uma trajetória unificada e um signo de dominação tanto do orientalismo como do colonialismo", Said apresenta como forma de reação ao discurso imperialista "os bem conhecidos valores do liberalismo humanista, ou seja, a tolerância, a acomodação, o relativismo e o pluralismo cultural." 50 Em Said, portanto, o discurso eurocêntrico é, ao mesmo tempo, remédio e veneno. É que Said critica precisamente a tradição que o constituiu como crítico, ou seja, a tradição dos estudos comparativos da literatura européia como praticados por "Auerbach, Curtius e Spitzer, os comparatistas germânicos que marcaram a disciplina com uma forma basicamente conservadora de humanismo clássico" ${ }^{\text {"1 }}$.

Ao praticar um humanismo eurocêntrico que, embora inseparável da ética imperialista, apresenta, ainda assim, um lado positivo em sua proposta de valorização da dignidade humana e da tolerância, e isso tentando evitar a todo o custo a filiação a sistemas ideológicos específicos, Said consegue, no entanto, desenvolver uma proposta de análise do discurso imperial com suficiente flexibilidade para abranger a diversidade de Histórias da alteridade, e não apenas a (Não-)História única do outro enquanto o negativo da historiografia do Ocidente. Recuperar tais Histórias esquecidas em uma análise textual capaz de revelar tanto as estratégias discursivas imperialistas no texto do colonizador como a resistência ao exercício discursivo de poder imperial nos textos do colonizado é a tarefa a que se propõe Said em Orientalismo e, mais recentemente, em Culture and Imperialism, este último enfatizando, mais do que o primeiro, a "experiência histórica de resistência ao império". ${ }^{52}$ À metodologia de leitura a ser usada em tal projeto de crítica do discurso imperial Said denomina "leitura em contraponto" ("contrapuntal reading"). Trata-se da leitura que, seja no mesmo texto, seja em textos diversos, procura sempre a duplicidade de significações em conflito. "A leitura em contraponto", diz Said, "leva em conta dois processos, o do imperialismo e o da resistência ao império, e pode ser feita pela expansão do foco da leitura de textos de tal forma que seja incluído aquilo que foi anteriormente excluído". ${ }^{53}$ Said, como Jameson, tem um projeto de estudo de

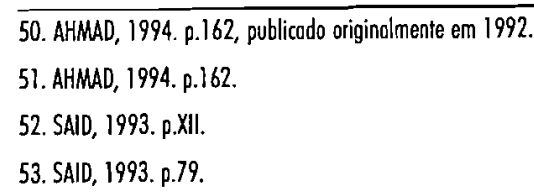


Literatura Comparada no qual se torne possível o resgate de Histórias textuais alternativas sem que, contudo, se caia nas limitações do nacionalismo xenófobo.

Perseguir, em um dado texto, tanto o excluído como o incluído significa evidentemente que o texto a ser lido já não pode ser visto como artefato fechado em si mesmo, auto-suficiente, e harmoniosamente integrado em termos de um todo que é maior do que cada uma de suas partes. $O$ texto torna-se, antes, um conjunto de vozes nem sempre harmônicas, freqüentemente em conflito não resolvido, e sempre excluindo outras vozes a serem resgatadas pela crítica "em contraponto". Um texto assim concebido é mais importante pelos seus conflitos e em seus silêncios do que pela sua superfície visível, já que é precisamente nesses silêncios e conflitos que é possível perceber "documentos ocultos" e "histórias esquecidas ou abandonadas". Vale dizer, é nos seus vazios, esvaziamentos e conflitos que o texto deixa transparecer, como mostrou Pierre Macherey, os limites da ideologia. São reveladores na medida em que constituem sintomas das fissuras que ameaçam a consistência de uma cultura com as contradições que o sistema não consegue nem absorver e nem esquecer ou excluir. ${ }^{54}$ A superfície visível de um texto como A Tempestade, de William Shakespeare, não deixa entrever muito sobre o processo de colonização do Novo Mundo. Não há nenhuma referência explícita à América no texto e a relação da peça com a expansão imperialista é aparentemente periférica e indireta, apesar de tratar-se de um texto situado precisamente no contexto histórico imediatamente posterior ao descobrimento e ao projeto de colonização (a peça é apresentada pela primeira vez em 1611). Essa presença periférica manifestada apenas em silêncios (ausência de referência específica à América) ou em sugestões aparentemente pouco significativas na trama da peça como um todo ("Caliban" como anagrama de "canibal") não interessa muito a uma crítica preocupada com um levantamento positivista dos grandes temas recorrentes na superfície textual. Para essa vertente crítica, o que importa é a oposição entre natureza e cultura, ou, mais precisamente, a natureza que não pode ser resgatada pela civilização, representada por Caliban, e a natureza que pode ser resgatada ("nurtured") pela cultura e pelo poder da imaginação criadora de Próspero. Para uma crítica em contraponto, contudo, são justamente esses silêncios e essas sugestões periféricas que, longe de constituírem apenas restos pouco significativos existentes na peça como um horizonte distante e pouco visível, tornam-se o foco de atenção e apontam (em um contexto de intertextualidade que inclui tanto o texto europeu de Próspero como o americano de Caliban) para aquilo que está sendo reprimido no texto, ou seja, a violência

54. MACHEREY, 1978. colonizadora. A peça de Shakespeare torna-se, assim, um documento literário profundamente comprometido com o projeto imperialista na medida em que, como mostrou Peter Hulme, o horizonte periférico pode e deve ser resgatado como tema central. Ao reler o clássico de Shakespeare em Colonial Encounters, Hulme mostra em detalhes não apenas a existência do inegável relacionamento entre o texto de Shakespeare e os documentos descritivos da colonização, conhecidos como os Panfletos das Bermudas (The Bermuda Pamphets), mas revela ainda a possibilidade de se ler a peça como centrada tematicamente não no mundo mediterrâneo de Próspero, mas no mundo atlântico de Caliban. ${ }^{55}$

A prática da leitura em contraponto em Said não se restringe, contudo, apenas a textos isolados. Pode e deve também ser uma prática intertextual de alcance globalizante capaz de aproximar textos do centro e da periferia, não, como no caso de Jameson, situando tais textos em uma História única, mas justapondo-os na sua complexidade enquanto práticas culturais (em contraste com mero artefatos) em contraponto:

Aproximar experiência e cultura significa, evidentemente, ler textos do centro metropolitano e das periferias em contraponto, não atribuindo nem o privilégio da "objetividade" para o "nosso lado", nem o fardo da "subjetividade" para o "deles". Trata-se do problema de saber como ler, como dizem os desconstrucionistas, e não separar essa questão de saber o que ler. Textos não são objetos acabados [...]. Se esses conceitos de contraponto, inter-relacionamento e integração significam algo mais do que uma sugestão patentemente celebratória de um ecumenismo de foco, tal significado existe na insistência da experiência histórica do imperialismo enquanto uma questão, em primeiro lugar, de histórias interdependentes e de dimensões sobrepostas, e, em segundo, de algo que torna obrigatórias as escolhas intelectuais e políticas [...] [através da interpretação dos] dois lados do argumento, não apenas em uma dimensão hermenêutica, mas também política. ${ }^{56}$

De forma simplificada, a proposta de Said resume-se, aqui, a expandir o conceito de leitura em contraponto para um nível globalizante e a partir de uma certa ética capaz de associar, de forma indissolúvel, a interpretação e o político na leitura de textos justapostos do centro e da periferia. Os textos

\section{HULME, 1986. p.89-134}

56. SAID, 1993. p.312.313. 
justapostos a serem lidos, é preciso insistir, não podem ser vistos como autônomos, mas como entidades incompletas não apenas porque contêm vazios, mas também porque constituem fragmentos culturais a serem relacionados a outros discursos da mesma ou de outras culturas. Um texto, como diz Said, "deve ser visto [...] em termos do seu passado e de interpretações futuras." 57 Assim entendida, a peça de Shakespeare, inerentemente incompleta em seus vazios, é também incompleta enquanto texto em expansão constante e em relação a novos textos produzidos com os quais existe em contraponto, sejam eles textos de interpretações alternativas ou textos que rescrevem o texto clássico para contestá-lo. Nesse contexto, uma forma de leitura em contraponto com o texto de Shakespeare trataria de lê-lo em contraste com o conjunto de textos formados pelas inúmeras apropriações que dele fizeram escritores provenientes dos espaços colonizados, como Roberto Fernándes Retamar ou Aimée Césaire. ${ }^{58}$

As obras de Edward Said e de Fredric Jameson representam, no contex to da crítica literária e cultural da atualidade, projetos alternativos para restaurar a validade do estudo histórico na leitura de textos, na dimensão globalizante da cultura metropolitana e das culturas periféricas. $O$ que esses projetos têm em comum, como se viu, é uma certa visão da natureza do texto literário ou cultural não apenas em termos de um valor estético civilizatório e humanizante, mas também sob a luz de uma estética que inevitavelmente prospera em virtude de sua cumplicidade com os sistemas de poder que a cerca. As propostas para se trabalharem textos assim considerados, porém, varia consideravelmente nos dois teóricos. Enquanto para Jameson trata-se sempre de situar tais textos em suas desigualdades e no contexto de uma História única e última e do sistema ideológico que a explica de maneira mais completa (em resumo, situar textos na história do movimento do capital e na perspectiva marxista), para Said, tais textos devem ser lidos a partir da prática relativamente livre do crítico, que, em precário equilíbrio entre cultura e sistema e munido de uma ética humanitária de valor universal, tenta uma leitura em contraponto dirigida para a percepção das Histórias do outro cultural reprimidas pelas estratégias discursivas imperiais. O que é, talvez, mais significativo nesses dois exemplos de crítica é a tentativa, que ocorre sistematicamente pela primeira vez na crítica contemporânea, de atribuir ao projeto crítico um alcance globalizante e capaz de incluir como objeto de estudo o que tinha sido antes excluído, ou seja, as Histórias culturais periféricas e suas vozes representativas. No âmbito da Literatura Comparada, por exemplo, o que se propõe é não apenas uma expansão do campo de estudos

57. SAID, 1993. p.79.

58. CÉSAIRE, 1969; RETAMAR, 1989. além do cânone ocidental ou europeu, mas ainda uma certa metodologia de leitura capaz de integrar o estético ao ético e ao político. Apesar das diversidades ideológicas e metodológicas, tais projetos não devem necessariamente ser considerados mutuamente excludentes. São, antes, formas problemáticas e complementares para se avaliar, hoje, e em termos de globalização, as complexas relações de cumplicidade e complementaridade entre cultura e poder mundano. Constituem paradigmas já institucionalmente consolidados e já utilizados criticamente por gerações mais jovens de críticos voltados para áreas como a crítica pós-colonial ou, alternativamente, Estudos Culturais. Se desses trabalhos mais recentes se pode dizer que muito realizaram, é preciso acrescentar logo que muito ainda há por fazer.

\section{ABSTRACT:}

The works of Edward Said and Fredric Jameson define, in the context of contemporary literary and critical practices, alternative projects devoted to restoring the validity of the historical perspective for the comprehension of texts in the global dimension of power which comprises both metropolitan and peripheral cultures. Whereas Jameson attemps to situate these texts in their differences and in the context of a unique, final history defined in terms of the ideological system capable of explaining it in the best possible manner (Marxism), Said sees texts as objects to be perceived by a critical exercise of relative freedom in which the figure of the critic, permanently living in the unstable balance between culture and systems of thought, tries to produce a contrapuntal reading with the purpose of incorporating the histories of the cultural other repressed by imperialist discourses. KEYWORDS:

Comparative Literature, Edward Said, Fredric Jameson, Literary Theory 


\section{A MÁQUINA TEÓRICA: O DISCURSO DE CHRISTOPHER NORRIS SOBRE O PÓS-MODERNISMO NA DÉCADA DE NOVENTA}

REFERÊNCIAS BIBLIOGRÁFICAS

AHMAD, Aijoz. "Culture, Notionolism, ond the Role of Intellectuals: An interview with Aijoz Ahomod". Monthly Review (july August) 41.70.

AHMAD, Aijoz. 1992. In Theory. London: Verso.

AIDRIDGE Owen. 1960. Comparative Literoture: Matter ond Method. urbono: U. of Illinois Ress.

BASSNET, Suson. 1993. Comporotive Literoture: A Critical Introduction. Oxtard: Blockwell.

BENJAMIM, Wolter. 1969. Illuminotions. New York: Schocken

BROOKS, Peter. 1995. "Must We Apologize?" Comparotive Literoture in the Age of Muliculturolism. Boltimore and London: The Johns Hopkins University Press.

CÉSAIRE, Airné. 1969. Une Tempếte; Adoptocion de Lo Tempête, de Shokespeore, pour un Théorte Nègre. Poris: Sevil.

FOUCAULI, Michel. 1961. Folie et Déroison: Histoire de lo Folie ò l'Áge Clossique. Paris: Gollimord.

FOUCAULI, Michel. 1976. "Questions of Geogrophy". In: Power ond Knowledge, ed. Colin Gordon. Brighton.

HULME, Peter. 1986. Colonial Encounters. London: Routledge.

JAMESÓN, Fredric. 1980. "Morxism ond Teaching". In: New Politicol Science 1, 2/3 (Foll-Winter), 31-36.

JaMESON"

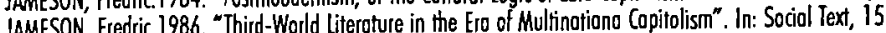

JAMESON, Fredric. 19870. "A Brief Response". In: Sociol Text, 17.

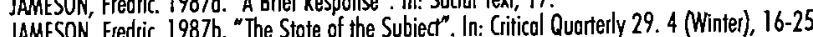

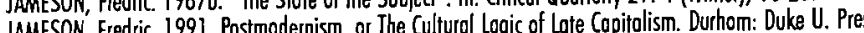

JuESON" Fedric 1996. "Five Theses on Aduolly Existing Moxism". In: Monthly Review 47, 11 (April 1996), 1-10.

MACHERÉ Piere. 1966. A Theon of Literon Production. London: Routledge 1978.

RETAMAR, Roberto Fennondes. 1989 Calibon: Notes Toward o Discussion of culture in Our Americo. Minneopalis: The University of Minneconto Press.

SAID, Edward. 19780. "The Problem of Textudity: Two Exemplory Positions". In: Critical Inquiry 4, vol. 4 number 4: 613-714.

SAID, Edword. 1978b. Orientolism. London: Chatto \& Windus.

SAID, Edword. 1993. Culture ond Impperiolism. London: Chatto \& Windus.

WALERSTEIN, Immonuel. 1974. The Modern World. System. 2 vols. New York: Acodernic press.

on The Political Unconscious" In: The Politics of Theory eds. Froncis Barker et

olii. Colchester: U. of Essex Press.

YOUNG, Robert. 1990. White Mythologies: Writing History ond the West. London: Routledge.
Adam Sharman

Universidade de Nottingham

RESUMO:

O presente ensaio oferece uma exegese crítica dos sete livros que, até o final de 1997, o teórico e crítico britânico Christopher Norman dedicou ao pós-modernismo, considerando-se que a temática de Norris é a teoria posmodernista, não os artefatos culturais ou processos pósmodernistas pelos quais ele demonstra pouco interesse. Nessa trajetória, são entrelaçados os fios de diversas questões: o entendimento de Norris do pós-modernismo; as objeções que ele faz à teoria pós-modernista; o teor de sua discordância de pensadores como Baudrillard com relação à Guerra do Golfo; a nota de desalento que pauta sua visão do pós-modernismo; o impacto do contexto político de direita de Margaret Thatcher sobre sua visão pessimista dos intelectuais pós-modernistas no início da década. Sobretudo, o ensaio rastreia a crítica reiterada de Norris à excessiva extensão conferida à lingüística saussureana, na sua opinião, a raiz de um mal-elaborado "relativismo cultural", bem como seu amplo comentario sobre o afastamento de Michel Foucault do pensamento de Kant. Norris crê que esse encontro ilustra, de forma exemplar, o afastamento pós-
REVISTA DE ESTUDOS DE LITERATURA 